\title{
Estimating evapotranspiration with ASTER thermal infrared imagery
}

\author{
A.N. French, T.J. Schmugge and W.P. Kustas \\ USDA/ARS Hydrology and Remote Sensing Laboratory
}

\begin{abstract}
The recent availability of multi-band thermal infrared imagery from the ASTER sensor has made feasible spatial estimation of evapotranspiration at 90 meter resolution. One critical variable in evapotranspiration models is surface temperature. With ASTER the temperature can be reliably determined over a wide range of vegetative conditions. The requirements for accurate temperature measurement include minimization of atmospheric effects, correction for surface emissivity variations and sufficient resolution for the type of vegetative cover. When ASTER imagery are combined with meteorological observations, these requirements are usually met and result in surface temperatures accurate within $1-2^{\circ} \mathrm{C}$. Other sensors, such as Landsat TM and AVHRR, do not meet these requirements because they either lack the resolution of ASTER, or because their broadband radiometers cannot correct for surface emissivity.

ASTER-based evapotranspiration estimates for a few days during 20002001 were made over the sub-humid grazing and wheat lands in central Oklahoma. Daily evapotranspiration was estimated by applying instantaneous
\end{abstract}

ASTER surface temperatures, as well as ASTER-based vegetation indices from visible-near infrared bands, to a two-source energy flux model and combining the result with separately acquired hourly solar radiation data. The estimates of surface fluxes show reasonable agreement $\left(50-100 \mathrm{~W} / \mathrm{m}^{2}\right)$ with ground-based eddy-correlation measurements and illustrate how ASTER measurements can be applied to heterogeneous terrain. There are some discrepancies, however, and these may in part be due to difficulty quantifying fractional cover of senescent vegetation.

\section{INTRODUCTION}

Estimating the spatial distribution of evapotranspiration is important for a variety of hydrological and meteorological pursuits, ranging from evaluation of crop health to global climate models. Typical approaches towards estimating evapotranspiration are developed around a surface energy balance model with four components: net radiation $(\mathrm{Rn})$, soil heat flux $(\mathrm{G})$, sensible heat flux $(\mathrm{H})$, and latent heat flux (LE). In these models, incoming solar energy energy is balanced by outgoing energy to the soil and the surface boundary layer. The desired evapotranspiration is represented by the LE component.

But spatially distributed surface energy flux estimates are difficult to make, especially over heterogeneous terrain. One of the most reliable techniques available for measuring surface fluxes is with eddy-covariance instruments, but experience has shown that there may be large variabilities in measurements at closely located sites. On the other hand, remote sensing techniques excel at characterizing spatial relationships of surface features, but cannot make critical observations of near surface temperatures, winds and humidity.

The most promising approach to measuring evapotranspiration, therefore, lies in using a model that combines groundbased measurements with reliably calibrated remote sensing data. In the past, this approach has been hindered by inadequate spatial resolutions and especially by unreliable surface temperature estimates. The recent availability of ASTER (Advanced Spaceborne Thermal Emission and Reflection radiometer) im- agery, however, has greatly reduced these limitations. ASTER is a sensor package onboard the recently launched Terra satellite with high resolution capabilities- ranging from 15 meters to 90 meters- and excellent surface temperature measuring capabilities.

Here we show results from the use of a relatively simple, physically-based surface energy flux model that incorporates ASTER observations in the visible, near infrared and thermal infrared along with commonly available surface meteorological observations. Resulting estimates of evapotranspiration appear to be reasonable and form a basis for further development of remote sensing based flux models.

\section{ESTIMATION OF EVAPOTRANSPIRATION}

The approach towards estimating evapotranspiration used in this study was to use an energy balance driven by ASTER observed vegetation indices and observed radiometric surface temperatures. The vegetation cover was estimated from NDVI observations at 15 meter resolution, while the radiometric surface temperature was estimated from multiband thermal infrared observations at 90 meter resolution. By using known relationships between total daily solar radiation and observations at a specific time, average daily evapotranspiration can be estimated.

This is essentially the same set of techniques previously used over the Southern Great Plains '97 study site (SGP97) at El Reno, Oklahoma [1]. SGP97 was a large field study over central Oklahoma to southern Kansas and which evaluated the spatial variations of soil moisture and surface energy fluxes during June-July 1997. In that study, energy fluxes were estimated by taking a set of remote sensing observations during the midmorning and computing the instantaneous surface fluxes with a model known as Two-Source Energy Balance (TSEB)[2]. In addition to the remote sensing observations, TSEB requires measurements of near surface air temperature, humidity and wind speed.

The essence of TSEB is the partitioning of the turbulent surface energy flux components - $\mathrm{H}$ and LE - into two sources: vegetation canopy and soil, for each surface element. The partitioning is accomplished by estimating fractional vegetative cover from the vegetation index NDVI, proportioning the observed radiometric temperatures accordingly, and constraining evapotranspiration with the Priestley-Taylor formulation [3]. Although the input requirements are modest, TSEB output is strongly controlled by physically meaningful observations, and less so by strictly empirical relationships.

The validity of TSEB has been established in several studies (e.g. [1] and [4]). Flux measurements from ground-based eddy-covariance instruments show good agreement in many in- 
stances with TSEB estimates, with typical discrepancies ranging between $25-75 \mathrm{~W} / \mathrm{m}^{2}$.

The potential reliability of evapotranspiration estimates from ASTER-based observations, however, is not only dependent upon the validity of the hydrological model, but also upon the reliability of estimated surface temperatures. The TSEB approach will only perform well if the observed radiometric temperatures are reliable and consistent. Results from SGP97 show that multiband thermal infrared observations, similar to those obtainable from ASTER, are substantially more reliable than single band observations obtained from Landsat or limited-band observations from AVHRR. For SGP97, the multiband thermal infrared TIMS instrument [5] was used, which is a remote sensing tool capable of measureing surface temperatures within $1^{\circ} \mathrm{C}$ over heterogeneous terrain. This is accomplished by accounting for surface emissivity variations through a technique referred to as Temperature-Emissivity Separation (TES) [6][7]. When the surface emissivity is close to 1.0, such as over uniformly and heavily vegetated fields, accounting for emissivity variations is unimportant, and surface temperatures can be reliably determined from well-calibrated single band thermal infrared radiometers. Over the SGP97 area, however, there were many instances where surface emissivity was significantly less than 1.0 and emissivity had to be considered when deriving surface temperatures.

\section{Results}

Because of our previous work with TSEB and remote sensing data at SGP97, and particularly because of our understanding of the distribution of vegetation and land uses, we have begun collecting ASTER imagery over the same area. The particular site is the USDA El Reno Grazinglands Research Laboratory. The fields typically span hundreds of meters and include grasslands, pasture and winter wheat. During SGP97, four eddy covariance stations made continuous measurements of surface fluxes, while wind speed, air temperature and relative humidity measurements were made from 10 meter towers. Unfortunately, these measurements are no longer being made. However, an extended facility within the core grasslands, containing Bowen Ratio instruments, does collect energy flux and local meteorological measurements [8]. These surface based measurements are expected to be reliable, and are representative of the more thickly vegetated portions of El Reno.

As shown in Table I, we have currently modeled ASTER scenes from 4 September and 27 September 2000. The results show reasonably close agreement for early September, when senescense was just beginning. Late Septmber results were improved when assumptions about vegetative cover were derived from SGP97 observations, rather than from ASTER observations directly. The results show that ASTER observations of surface temperature and NDVI are as expected and that reliable surface flux estimates are feasible. The discrepancy for late September highlights a difficulty encountered by all remote sensing energy flux models, namely how to quantify vegetative cover during senescence.

Integration of the instantaneous LE values from 4 September observations resulted in a daily evapotranspiration image (Fig. 1). The patterns are consistent with known land uses: low evapotranspiration over dry, unvegetated soils, and higher evapotran- spiration over well vegetated fields. Water bodies and riparian zones also show relatively high evapotranspiration.

\section{REFERENCES}

[1] A. N. French, T.J. Schmugge, and W.P. Kustas. Estimating surface fluxes over the sgp site with remotely sensed data. Phys. Chem. Earth (B), 25(2):167-172, 2000.

[2] J.M. Norman, W.P. Kustas, and K.S. Humes. A two-source approach for estimating soil and vegetation energy fluxes from observations of directional radiometric surface temperature. Agric. For. Meteorol., 77:263-293, 1995.

[3] C.H.B. Priestley and R.J. Taylor. On the assessment of surface heat flux and evaporation using large-scale parameters. Monthly Weath. Rev., 100:81-92, 1972.

[4] W.P. Kustas and J.M. Norman. Evaluation of soil and vegetation heat flux predictions using a simple two-source model with radiometric temperatures for partial canopy cover. Agric. For. Meteorol., 94:13-29, 1999.

[5] Frank Don Palluconi and Gerald R. Meeks. Thermal infrared multispectral scanner (TIMS): an investigator's guide to TIMS data. Technical Report JPL publication 85-32, Jet Propulsion Laboratory, California Institute of Technology, Pasadena, California, 1985.

[6] T. Schmugge, S.J. Hook, and C. Coll. Recovering surface temperature and emissivity from thermal infrared multispectral data. Remote Sens. Environ., 65:121-131, 1998.

[7] A.R. Gillespie, S. Rokugawa, T. Matsunaga, J.S. Cothern, S. Hook, and A.B. Kahle. A temperature and emissivity separation algorithm for advanced spaceborne thermal emission and reflection radiometer (ASTER) images. IEEE Trans. on Geo. Remote Sens., 36:1113-1126, 1998.

[8] USDA Natural Resources Conservation Service. Soil Climate Analysis Network. http://www.wcc.nrcs.usda.gov/scan/site.pl?sitenum=2022\&state $=0 k$. 
TABLE I

ASTER DERIVED SURFACE ENERGY FLUXES AT THE USDA SCAN SITE IN EL RENO, OKLAHOMA COMPARED WITH BOWEN RATIO MEASUREMENTS.

THE ADJUSTED 27 SEPTEMBER VALUE WAS COMPUTED IN THE SAME WAY AS THE ADJUSTED VALUE EXCEPT THAT THE FRACTIONAL SENESCENT VEGETATIVE COVER WAS INCREASED FROM AN LAI OF 0.8 TO AN LAI OF 3.0.

\begin{tabular}{|c|c|c|c|c|c|c|c|c|}
\hline Date & \multicolumn{2}{|c|}{$\mathrm{H}$} & \multicolumn{2}{c|}{ LE } & \multicolumn{2}{c|}{ G } & \multicolumn{2}{c|}{ Rn } \\
\hline & TSEB & Bowen & TSEB & Bowen & TSEB & Bowen & TSEB & Bowen \\
\hline 4 Sept & 198 & 249 & 180 & 236 & 106 & 26 & 483 & 510 \\
\hline 27 Sept & 203 & 403 & 153 & 97 & 95 & 28 & 451 & 528 \\
\hline 27 Sept (adj) & 390 & 403 & 51 & 97 & 62 & 28 & 502 & 528 \\
\hline
\end{tabular}
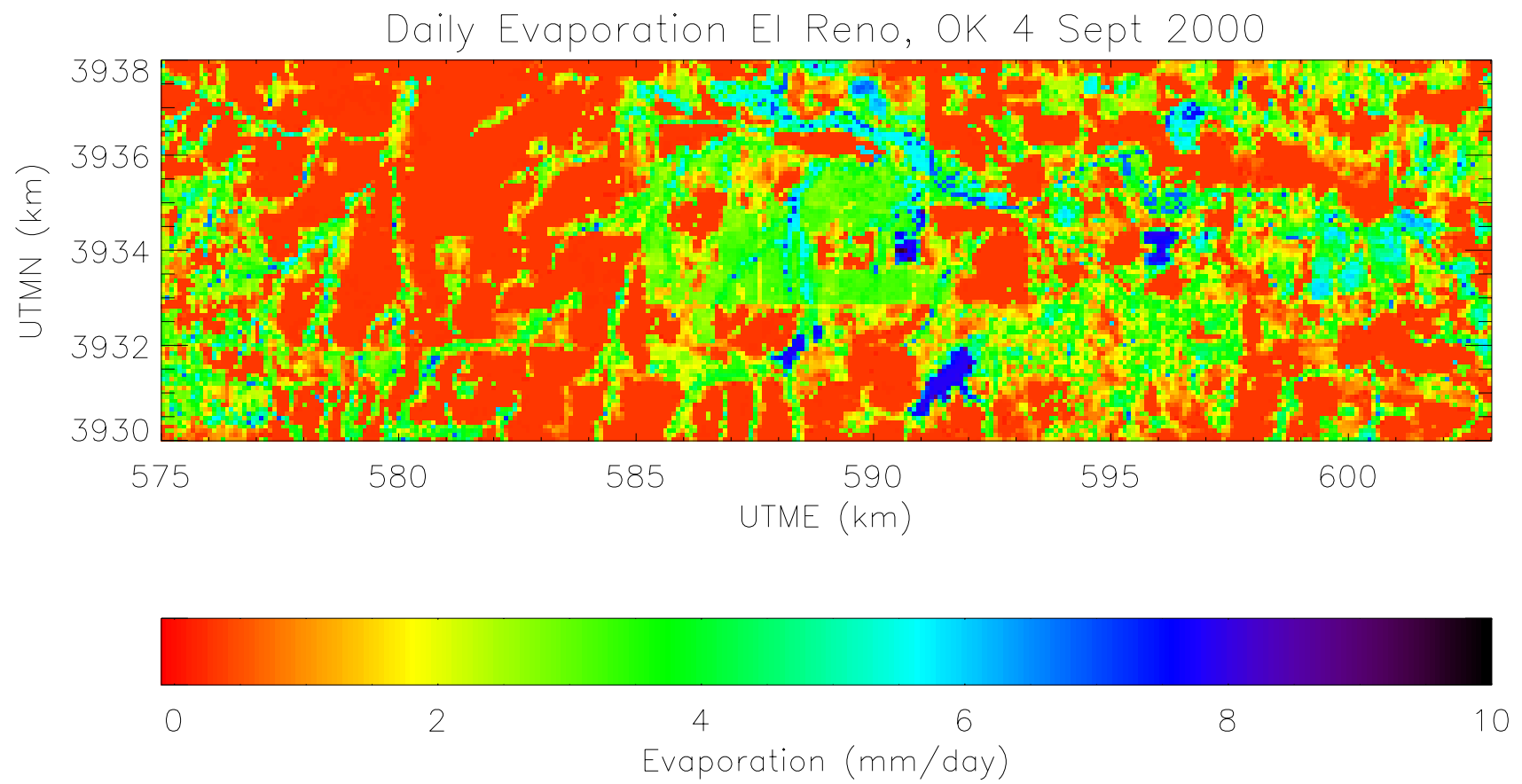

Fig. 1. Estimated daily evapotranspiration over the El Reno, Oklahoma study area using ASTER observation at $\approx 11: 30$ am. A drought occurred during the summer of 2000 , and by September many of the fields were either plowed or contained senescent vegetation. In this image, 0-1 (red) corresponds to dry soils, 4 (green) to grass lands, and 6-8 (blue) to lakes, ponds and riparian zones. 